\title{
Research Paper: Effects of Upper Extremity Coordination Exercises Based on Fatigue Prediction on Upper Extremity Sensory-motor Functions in Chronic Stroke Survivors
}

\author{
Samira Fathi $^{1}$ (D), Ghorban Taghizadeh ${ }^{1}$ (D), Akram Azad ${ }^{1}$ (D), Saeed Behzadipour ${ }^{2}$ (D), Danial Shams Hafshejani ${ }^{1}$ (D), Alireza Zare ${ }^{2}$ (D), Zahra \\ Ghorbanpour $^{3}$ (i) \\ 1. Rehabilitation Research Center, Department of Occupational Therapy, School of Rehabilitation Sciences, Iran University of Medical Sciences, Tehran, Iran \\ 2. Department of Mechanical Engineering, Sharif University of Technology, Tehran, Iran. \\ 3. Department of Occupational Therapy, School of Rehabilitation Sciences, University of Social Welfare and Rehabilitation Sciences, Tehran, Iran.
}

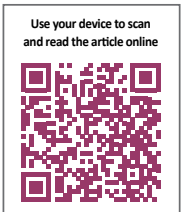

Cftatton Fathi S, Taghizadeh G, Azad A, Behzadipour S, Shams Hafshejani D, Zare A. Effects of Upper Extremity Coordination Exercises Based on Fatigue Prediction on Upper Extremity Sensory-motor Functions in Chronic Stroke Survivors Iranian Rehabilitation Journal. 2022; 20(Special Issue):17-28. http://dx.doi.org/10.32598/irj.20.Speciallssue.626.8

doi $h$ http://dx.doi.org/10.32598/irj.20.Speciallssue.626.8

Article info:

Received: 24 Jun 2021

Accepted: 01 Sep 2021

Available Online: 01 Jan 2022

\section{Keywords:}

Stroke, Upper extremity,

Fatigue, Activity of daily living, Motor function

\section{A B STRACT}

Objectives: This study aimed to investigate the effect of upper extremity coordination exercises based on fatigue prediction on fine and gross manual dexterity, upper limb motor function, shoulder and elbow proprioception, occupational performance, and activities of daily living in chronic stroke survivors.

Methods: In this pilot double-blind randomized clinical trial, 24 chronic strokes were enrolled using the non-probability sampling method. Participants were randomly allocated to the control (received routine occupational therapy) and intervention (received upper extremity coordination exercises based on fatigue prediction using the Kinect) groups. Before and after the interventions (six weeks, three sessions/week, $45 \mathrm{~min} / \mathrm{session}$ ), as well as six weeks after completion of interventions, participants were assessed using the following tools: Box-Block Test, Purdue-Pegboard Test, Wolf-Motor Function Test, Action Research Arm Test, Manual Ability Measure-16, Grip Dynamometer, Shoulder Position Sense Test (SPST), Elbow Position Sense Test (EPST), Canadian Occupational Performance Measure, Shah-Barthel Index (SH-BI), and Multi-dimensional Fatigue Inventory. This project was carried out in the rehabilitation department of Shafa-Yahyaeian Hospital from May 2019 to June 2020

Results: The results showed a significant improvement in all assessments of both control and intervention groups ( $\mathrm{P} \leq 0.05)$, except for SH-BI. Further, the improvement of EPST and SPST scores in the intervention group was significantly greater than the control group $(\mathrm{P} \leq 0.05)$. Also, a significant decrease in fatigue severity was observed in both control and intervention groups $(\mathrm{P} \leq 0.05)$.

Conclusion: These results suggest that upper extremity coordination exercises based on fatigue prediction in combination with routine occupational therapy could lead to improvement of upper extremity sensory-motor functions and power grip and caused a decrease in fatigue severity in chronic stroke.

\section{* Corresponding Author:}

Akram Azad, PhD.

Address: Rehabilitation Research Center, Department of Occupational Therapy, School of Rehabilitation Sciences, Iran University of Medical Sciences,

Tehran, Iran.

Tel: +98 (912) 2863974

E-mail:azad.a@iums.ac.ir 


\section{Highlights}

- Upper extremity coordination exercises based on fatigue prediction can improve upper extremity sensory-motor functions, power grip, and participation in stroke patients.

- Upper extremity coordination exercises based on fatigue prediction can significantly decrease fatigue severity in stroke patients.

- Upper extremity coordination exercises based on fatigue prediction did not show any significant effect on activities of daily living.

\section{Plain Language Summary}

Post-stroke fatigue is a common consequence of stroke. Peripheral fatigue is the most common type of physical fatigue that leads to needing help and the inability to control daily life as reported by stroke survivors. Moreover, fatigue may reduce the efficiency of rehabilitation interventions. Predicting fatigue may enhance the duration and number of exercises performed in a rehabilitation session. Based on motor learning principles, increasing the number of exercises plays an important role in motor learning and its consolidation. In this study, Kinect was used to measure the level of fatigue and provide fatigue feedback to the participants during upper extremity coordination exercises. In our study, 12 stroke patients performed upper extremity coordination exercises based on fatigue prediction using the Kinect. The results of this study showed a significant improvement in upper extremity motor functions, shoulder and elbow proprioception, grip strength, and occupational performance and satisfaction of occupational performance, as well as a significant reduction in fatigue severity in both control and intervention groups. However, the findings of this study showed that independence in activities of daily life evaluated by SH-BI did not change significantly following receiving exercises in the control or intervention group.

\section{Introduction}

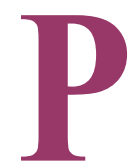

ost-stroke fatigue is a common consequence of stroke, affecting about $29 \%$ to $72 \%$ of stroke survivors [1]. Peripheral fatigue is the most common type of physical fatigue, which occurs in muscles and motor units and leads to reduced sensory-motor functions [2]. Fatigue leads to needing help and inability to control daily life as reported by stroke survivors. Moreover, the negative impact of fatigue is evident on sleep, participation, returning to work, driving, and other functions of stroke survivors. It has been shown that physical exercise has benefits for common post-stroke problems, including fatigue [3]. Although it has been shown that intensive training is needed to obtain the best rehabilitation efficiency, the occurrence of fatigue during rehabilitation exercises reduces patients' motivation, which has an important role in motor learning. Thus, fatigue may reduce the efficiency of rehabilitation interventions [4].

In addition to fatigue, stroke may cause spasticity, muscle weakness, and motor impairments of the Upper Extremity (UE). This may impair coordination between UEs, which has an important role in bimanual object manipulation. Lack of this coordination leads to dependence in Activities of Daily Living (ADLs) [5]. One of the rehabilitation exercises is the UE coordination exercise, in which both UEs are used to perform an activity. Indeed, in this type of exercise, unaffected UE is used to promote the functional recovery of the affected upper limb [6]. Since many human daily activities require the coordination of both hands, UE coordination exercises may be useful in the rehabilitation of stroke survivors [7]. However, fatigue prediction has not been considered in designing UE exercises in these patients. Predicting fatigue may enhance the duration and number of exercises performed in a rehabilitation session. Based on motor learning principles, increasing the number of exercises is required for motor learning and its consolidation [8]. Thus, it is possible to obtain better results from rehabilitation exercises by predicting early fatigue during exercises and changing the type of exercise. Hence, this study aimed to examine the effects of UE coordination exercises based on fatigue prediction on the UE sensorymotor functions and ADLs in chronic stroke survivors. 


\section{Materials and Methods}

This was a pilot randomized clinical trial study. Participants were randomly allocated to either the control group (routine occupational therapy intervention) or the intervention group (UE coordination exercises based on fatigue prediction by the Kinect), in a ratio of $1: 1$, using a permuted block randomization method. However, matching was not done in the current study. The randomization was carried out by an individual who was not involved in the study. Both participants, the examiner, and the occupational therapist with five years of clinical experience were blind to the group allocation. This project was carried out in the rehabilitation department of Shafa-Yahyaeian Hospital from May 2019 to June 2020. A consort statement was used to conduct and report this trial (Figure 1).

\section{Participants}

Participants were recruited from rehabilitation clinics of Shafa-Yahyaeian Hospital and Firoozgar Hospital in Tehran using the non-probability sampling method. Inclusion criteria were as follows: a history of a first-ever middle cerebral artery stroke diagnosed by a neurologist based on Magnetic Resonance Imaging; more than six months after stroke; the Brunnstrom recovery stage 4 or higher; acceptable cognitive function (i.e. Mini-Mental Status Examination score greater than 21); no unilateral visuospatial neglect (i.e. Star Cancelation Test score greater than 44); no moderate or severe depression (i.e. Beck Depression Inventory score lower than 29); and no orthopedic, rheumatologic, or other neurologic disorders affecting UE function. Participants were excluded in the case of a recurrent stroke or unwillingness to continue to participate in the study.

\section{Assessment tools}

Kinect: In the present study, type the Kinect II sensor was used. This device was used to measure the level of fatigue and provide fatigue feedback to the participants during UE coordination exercises. These data can be saved using specific software. On the other hand, due to the repetitive nature of the exercises, the recorded time series has a repetitive pattern, with the difference due to fatigue and differences in control strategies, the amplitude and local frequency of each cycle are different from other cycles. These are the differences and changes in the fatigue information carrier that can be extracted by nonlinear dynamic methods $[9,10]$.
Box \& Block Test (BBT): BBT is scored based on the number of blocks transferred from one side of the test box to the other in 1 minute. Only the affected hand was tested using the BBT in the current study. High test-retest reliability and good validity have been reported for the BBT [11].

Purdue Pegboard Test (PPT): PPT subscores include the number of pegs for the unimanual subtest, the number of pairs of pegs for the bimanual subtest, and the number of assembly components (peg, first collar, washer, and second collar) for the assembly subtest. The PPT has a high test-retest reliability [11].

Wolf Motor Function Test (WMFT): WMFT measures the ability and time to perform different motor functions with 15 items. The ability to perform each function is scored from 0 (no attempt to perform the function with the affected UE) to 5 (performs motor functions with the affected UE and the movements appear normal). The WMFT-ability is the mean of ability scores of the items. The WMFT-Time is the median time spent on completing items. It has been reported that WMFT has a high test-retest and inter-rater reliability in stroke survivors [11].

Action Arm Reach Test (ARAT): ARAT is an observational test for assessing UE motor function and coordination, which includes 19 items. Each item is scored on a 4 -point scale from $0=$ No movement to $3=$ Normal movement, leading to a total score of $0-57$. Hsieh et al. reported a very high inter-rater reliability of ARAT in stroke survivors [12].

Manual Ability Measurement-16 (MAM 16): MAM 16 measures the simplicity of performing ADLs with 16 items, each of them is scored on a 5-point Likert scale from 0 (I almost never do) to 4 (easy). The minimum score of this tool is 0 and the maximum score is 64 [13].

Dynamometer: A dynamometer was used to evaluate grip strength. The participant was instructed to press the dynamometer for 5 seconds and the force was recorded in kilograms. The test was performed in three trials and the mean recorded force of the three trials was calculated [14]. Coldhm et al. reported that the grip strength test, using a dynamometer in healthy subjects, has high reliability (ICC $>0.9)$ [15].

Shoulder Position Sense Test (SPST): To conduct this test, the patient is asked to actively reproduce 20 shoulder angles while his/her eyes are closed. The SPST score is calculated as the mean of differences between the ex- 
aminer-induced shoulder angles and patient-reproduced shoulder angles. The mean error in 20 shoulder angles shows the proprioceptive ability [16]. Dover et al. reported high test-retest reliability and inter-rater reliability $(\mathrm{ICC}=0.97-0.98)$ of the SPST in healthy subjects [17].

Elbow Position Sense Test (EPST): To perform this test, the patient is asked to actively reproduce 10 elbow angles while his/her eyes are closed and its score is calculated as the mean of differences between the examiner-induced elbow angles and patient-reproduced elbow angles. Kristensen et al. reported high test-retest reliability of the EPST in healthy subjects [18].

SH-Barthle Index (HS-BI): HS-BI includes 11 items, each of which is scored from 0 to 15 depending on the individual's condition and the nature of the item. The total score of SH-BI ranges from 0 to 100 , with a greater score indicating higher independence in ADLs. High inter-rater reliability of the Persian version of SH-BI has been reported in the elderly residing in nursing homes [19].

Canadian Occupational Performance Measure (COPM): COPM determines gradual changes in a person's perception of his/her function and satisfaction in each of the self-care, productivity, and leisure areas (COMPPerformance, and COPM-Satisfaction, respectively) [20]. Cup et al. reported that test-retest reliability of the COPM was good for the performance and satisfaction scores and its discriminant validity was confirmed [21].

Multidimensional Fatigue Inventory (MFI): MFI is a 20-item questionnaire with a total score of 1 to 100 , indicating the minimum and maximum amount of fatigue, respectively [22].

\section{Interventions}

The control group received routine occupational therapy intervention (six weeks, three sessions per week, 45 min per session), including stretching exercises for the intrinsic muscles of the affected hand, weight-bearing exercises on the affected hand and both hands, range of motion exercises, finger ladder exercises for shoulder flexion and abduction, sanding exercises using affected UE and both UEs, and exercises designed based on Brunnstrom treatment approach and Proprioceptive Neuromuscular Facilitation approach.

The intervention group received UE coordination exercises based on fatigue prediction using the Kinect (six weeks, three sessions per week, 30 min per session) in addition to the traditional rehabilitation (15 min per session). Bimanual exercises based on fatigue prediction.

To perform the UE coordination exercises, the participants sat on a chair without arm rests in front of a heightadjustable table and performed three bilateral shoulder movements, including flexion/extension, abduction/ adduction, and horizontal abduction/adduction at three heights (i.e., below shoulder level, parallel to shoulder level, and above shoulder level) [23]. During each of these movements, small or large cylindrical objects, cones, cubes, or balls were placed in the participant's hand. To predict fatigue during UE coordination exercises, the Kinect was placed 1.5 meters in front of the patient's chair. The participant's fatigue was predicted by the Kinect based on the number of repetitions performed for each of the three types of above-mentioned movements. When the participant's fatigue in one type of these movements reached $70 \%$, the type of movement was changed. Data collection was performed in rehabilitation clinics of Shafa-Yahyaeian Hospital in Tehran from May 2019 to June 2020. Analysis of the Kinect data was performed by a program written by an experienced biomechanical engineer. All assessments were performed in two hours during two sessions (with an average break of 2-3 minutes between assessments) by an occupational therapist with 5 years of clinical experience. All interventions were done by the first author.

Assessments were done by the same examiner three times: pre-treatment, post-treatment, and follow-up (i.e., 6 weeks after the interventions ended). BBT and PPT tests were used to evaluate gross and fine manual dexterity, respectively. Motor function of UE was assessed by the WMFT, ARAT, and MAM-16 tests. Shoulder and elbow proprioception was measured by the SPST and EPST tests, respectively. Occupational performance and satisfaction of occupational performance were evaluated using the COPM. SH-BI and MFI were used to evaluate independence in ADLs and fatigue severity, respectively. All assessments were performed in one session in random order.

\section{Statistical analysis}

The Shapiro-Wilk test was done to assess the normal distribution of data. The main effect of group (control and intervention groups) and time (pre-treatment, posttreatment, and follow-up) and their interaction effect on different outcome measures (i.e., UE sensory and motor functions, gross and fine manual dexterity, independence in ADLs, occupational performance, and satisfaction of occupational performance) were analyzed by a $2 \times 3$ two- 
way analysis of variance. Bonferroni post hoc test was conducted for multiple comparisons.

\section{Results}

A total of 110 chronic stroke survivors were screened, and 24 cases met the inclusion criteria and were randomly allocated to the control $(n=12)$ or intervention $(n=12)$ group. The Mean \pm SD age was $59.50 \pm 12.10$ years in the control group and $51.91 \pm 11.85$ years in the intervention group. There was not a significant difference between the control and intervention groups in terms of clinical and demographic characteristics, except for gender. Descriptive data of participants' characteristics are depicted in Table 1. The Mean \pm SD of the outcome measures is shown in Table 2.

The results of this study revealed that the main effect of the group was not significant for gross and fine manual dexterity assessed by BBT and PPT (unimanual, bimanual, and assembly subtests), respectively. However, the main effect of time was significant for the BBT score and assembly subscore of PPT. Also, the group $\times$ time interaction effect was only significant for the PPT bimanual subscore $(\mathrm{P}<0.05)$ (Table 3$)$. The results of multiple comparisons showed significant improvement in PPT bi- manual subscore in both control and intervention groups at post-treatment, which was remained at follow-up only in the control group (Figure 2).

Regarding the UE motor function (measured by WFTFunctional ability, WFT-Time, ARAT, and MAM-16), grip strength, occupational performance, and satisfaction of occupational performance (evaluated by COPMPerformance and COPM-Satisfaction), the main effect of group and the interaction effect of group $\times$ time were not significant. However, the main effect of time was significant $(\mathrm{P}<0.05)$ (Table 3$)$, indicating the significant improvement in UE motor function, grip strength, occupational performance, and satisfaction of occupational performance in both control and intervention groups. No significant difference was found between the control and intervention groups regarding these outcome measures.

Further, the results showed a significant main effect of time and group as well as their interaction effect on elbow proprioception of the affected side measured by EPST $(\mathrm{P}<0.05)$ (Table 3$)$. The results of multiple comparisons revealed significant improvement in elbow proprioception in both control and intervention groups at post-treatment, which was remained at follow-up only in the intervention group (Figure 3).

Table 1. Demographic and clinical characteristic of the participants

\begin{tabular}{|c|c|c|c|}
\hline \multirow[b]{2}{*}{ Characteristics } & \multicolumn{2}{|c|}{ No. (\%)/Mean \pm SD (Range) } & \multirow{2}{*}{$\begin{array}{c}\text { P } \\
\text { Between Groups }\end{array}$} \\
\hline & $\begin{array}{c}\text { Control Group } \\
(n=12)\end{array}$ & $\begin{array}{l}\text { Intervention Group } \\
(n=12)\end{array}$ & \\
\hline Sex (female/male) & $3 / 9$ & $9 / 3$ & 0.01 \\
\hline Dominant side (right/left) & $10 / 2$ & $12 / 0$ & 0.14 \\
\hline Affected side (right/left) & $7 / 5$ & $9 / 3$ & 0.38 \\
\hline Lesion type (ischemia/hemorrhage) & $5 / 7$ & $4 / 8$ & 0.67 \\
\hline Age (y) & $\begin{array}{c}59.50 \pm 12.10 \\
(33-79)\end{array}$ & $\begin{array}{c}51.91 \pm 11.85 \\
(32-69)\end{array}$ & 0.15 \\
\hline Times since stroke (month) & $\begin{array}{c}56.41 \pm 44.53 \\
(14-136)\end{array}$ & $\begin{array}{c}74.08 \pm 87.37 \\
(12-312)\end{array}$ & 0.77 \\
\hline Brunnstrom stage of motor recovery for upper extremity & $\begin{array}{l}4(4) \\
5(5) \\
3(6)\end{array}$ & $\begin{array}{l}4(4) \\
2(5) \\
6(6)\end{array}$ & 0.32 \\
\hline MMSE (score) & $\begin{array}{c}28.75 \pm 2.49 \\
(21-30)\end{array}$ & $\begin{array}{c}27.25 \pm 3.16 \\
(21-30)\end{array}$ & 0.07 \\
\hline BDI (score) & $\begin{array}{c}4.83 \pm 3.85 \\
(0-10)\end{array}$ & $\begin{array}{c}6.91 \pm 5.66 \\
(0-21)\end{array}$ & 0.52 \\
\hline
\end{tabular}

MMSE: Mini Mental State Examination; BDI: Beck Depression Inventory.

Iranian Rehabilitation \ourna 
Table 2. Descriptive data (Mean \pm SD) for outcomes measures at pre-treatment, post-treatment and follow-up

\begin{tabular}{|c|c|c|c|c|c|c|c|}
\hline & \multirow{2}{*}{ Variables } & \multicolumn{3}{|c|}{$\begin{array}{l}\text { Control Group } \\
(n=12)\end{array}$} & \multicolumn{3}{|c|}{$\begin{array}{l}\text { Intervention Group } \\
\qquad(n=12)\end{array}$} \\
\hline & & $\begin{array}{l}\text { Pre-treat- } \\
\text { ment }\end{array}$ & $\begin{array}{l}\text { Post-treat- } \\
\text { ment }\end{array}$ & Follow-up & $\begin{array}{l}\text { Pre-treat- } \\
\text { ment }\end{array}$ & $\begin{array}{l}\text { Post-treat- } \\
\text { ment }\end{array}$ & Follow-up \\
\hline \multirow{4}{*}{$\begin{array}{l}\text { Motor } \\
\text { Coordination } \\
\text { of UE }\end{array}$} & $\begin{array}{l}\text { Fine Motor Coordination of UE- } \\
\text { affected hand: PPT } \\
\text { (Number of pins per } 30 \text { seconds) }\end{array}$ & $5.58 \pm 4.87$ & $6.16 \pm 4.70$ & $5.66 \pm 4.63$ & $3.91 \pm 3.57$ & $4.50 \pm 3.45$ & $4.25 \pm 4.47$ \\
\hline & $\begin{array}{l}\text { Fine Motor Coordination of UE- } \\
\text { Two hand: PPT } \\
\text { (Number of pins per } 30 \text { seconds) }\end{array}$ & $4.25 \pm 4.30$ & $5.08 \pm 4.12$ & $4.41 \pm 3.77$ & $3.0 \pm 2.73$ & $3.33 \pm 3.20$ & $4.16 \pm 4.01$ \\
\hline & $\begin{array}{l}\text { Fine Motor Coordination of UE- } \\
\text { Montage: PPT } \\
\text { (Number of pins per } 30 \text { seconds) }\end{array}$ & $1.16 \pm 1.02$ & $1.58 \pm 1.24$ & $1.41 \pm 1.08$ & $1.25 \pm 1.28$ & $1.5 \pm 1.31$ & $1.41 \pm 1.37$ \\
\hline & $\begin{array}{l}\text { Gross Motor Coordination of } \\
\text { UE-affected hand: BBT } \\
\text { (Number of blocks per } 60 \\
\text { seconds }\end{array}$ & $21.25 \pm 15.65$ & $23.66 \pm 16.21$ & $23.25 \pm 16.29$ & $23.58 \pm 15.29$ & $26.25 \pm 16.19$ & $26 \pm 16.32$ \\
\hline \multirow{4}{*}{$\begin{array}{l}\text { Motor } \\
\text { function } \\
\text { of UE }\end{array}$} & $\begin{array}{l}\text { MAM-16 } \\
(0-64)\end{array}$ & $42.33 \pm 20.78$ & $44.75 \pm 20.70$ & $44.5 \pm 21.16$ & $40 \pm 17.24$ & $45.25 \pm 14.25$ & $46.4 \pm 14.14$ \\
\hline & $\begin{array}{l}\text { WMFT-Functional Ability } \\
(0-75)\end{array}$ & $68.75 \pm 14.72$ & $66.16 \pm 19.18$ & $70.41 \pm 15.63$ & $71.41 \pm 13.74$ & $73.25 \pm 11.66$ & $72.75 \pm 11.28$ \\
\hline & $\begin{array}{l}\text { WMFT-Time } \\
\text { (seconds) }\end{array}$ & $38.66 \pm 39.15$ & $35.41 \pm 40.49$ & $36.37 \pm 40.19$ & $42.58 \pm 47.40$ & $39.16 \pm 49.25$ & $40.41 \pm 48.85$ \\
\hline & $\begin{array}{l}\text { ARAT } \\
(0-57)\end{array}$ & $42 \pm 19.22$ & $43.41 \pm 18.97$ & $43.33 \pm 19.54$ & $44.25 \pm 18.64$ & $46.41 \pm 16.25$ & $45.58 \pm 16.96$ \\
\hline $\begin{array}{l}\text { Power } \\
\text { grasp of UE }\end{array}$ & $\begin{array}{l}\text { Dynamometer } \\
(\mathrm{Kg})\end{array}$ & $17.12 \pm 9.24$ & $23.93 \pm 20.37$ & $18.80 \pm 9.87$ & $15.72 \pm 10.01$ & $19.26 \pm 10.96$ & $19.07 \pm 10.28$ \\
\hline $\begin{array}{l}\text { Function of } \\
\text { shoulder } \\
\text { propriocep- } \\
\text { tion sense } \\
\text { on Affected } \\
\text { side }\end{array}$ & $\begin{array}{l}\text { Average error recognition of } \\
\text { angle on the shoulder: SPST } \\
\text { (degree) }\end{array}$ & $7.02 \pm 5.31$ & $5.51 \pm 4.36$ & $5.77 \pm 5.10$ & $6.08 \pm 6.06$ & $5.59 \pm 4.67$ & $4.55 \pm 5.27$ \\
\hline $\begin{array}{c}\text { Function } \\
\text { of Elbow } \\
\text { Propriocep- } \\
\text { tion Sense } \\
\text { on Affected } \\
\text { side }\end{array}$ & $\begin{array}{l}\text { Average error recognition of } \\
\text { angle on the elbow: EPST } \\
\text { (degree) }\end{array}$ & $7.80 \pm 6.87$ & $6.18 \pm 5.56$ & $6.72 \pm 6.40$ & $6.05 \pm 3.94$ & $4.29 \pm 2.88$ & $3.94 \pm 2.96$ \\
\hline \multirow{2}{*}{$\begin{array}{l}\text { Participa- } \\
\text { tion }\end{array}$} & $\begin{array}{l}\text { COPM-Performance } \\
(0-10)\end{array}$ & $5.97 \pm 2.05$ & $6.93 \pm 1.65$ & $7.12 \pm 1.63$ & $5.73 \pm 1.89$ & $6.5 \pm 1.84$ & $6.7 \pm 1.77$ \\
\hline & $\begin{array}{c}\text { COPM-Satisfaction } \\
(0-10)\end{array}$ & $5.74 \pm 2.54$ & $6.8 \pm 2.06$ & $7.15 \pm 1.73$ & $5.6 \pm 2.05$ & $6.15 \pm 1.8$ & $6.35 \pm 1.78$ \\
\hline $\begin{array}{l}\text { Activity of } \\
\text { Daily living }\end{array}$ & $\begin{array}{l}\text { SH-BI } \\
(0-100)\end{array}$ & $97.7 \pm 11.08$ & $97.4 \pm 7.55$ & $97.1 \pm 8.49$ & $98 \pm 4.32$ & $98.4 \pm 4.4$ & $98.4 \pm 4.4$ \\
\hline Fatigue & $\begin{array}{c}\text { MFI } \\
(1-100)\end{array}$ & $40.50 \pm 13.07$ & $38.33 \pm 10.87$ & $39.83 \pm 11.21$ & $39.91 \pm 8.42$ & $36.91 \pm 7.93$ & $39.58 \pm 8.56$ \\
\hline
\end{tabular}

Пranian Rehabilitation \ournal

PPT: Purdue and Pegboard Test; BBT: Box and Block Test; MAM-16: Manual Ability Measure-16; WMFT: Wolf Motor Function Test; ARAT: Action Research Arm Test; SPST: Shoulder Position Sense Test; EPST: Elbow Position Sense Test, COPM-performance: Canadian Occupational Performance Measure-performance; COPM-Satisfaction: Canadian Occupational Performance Measure-Satisfaction; SH-BI: Shah-Barthel Index, MFI: Multi-dimensional Fatigue Inventory, UE: Upper Extremity 


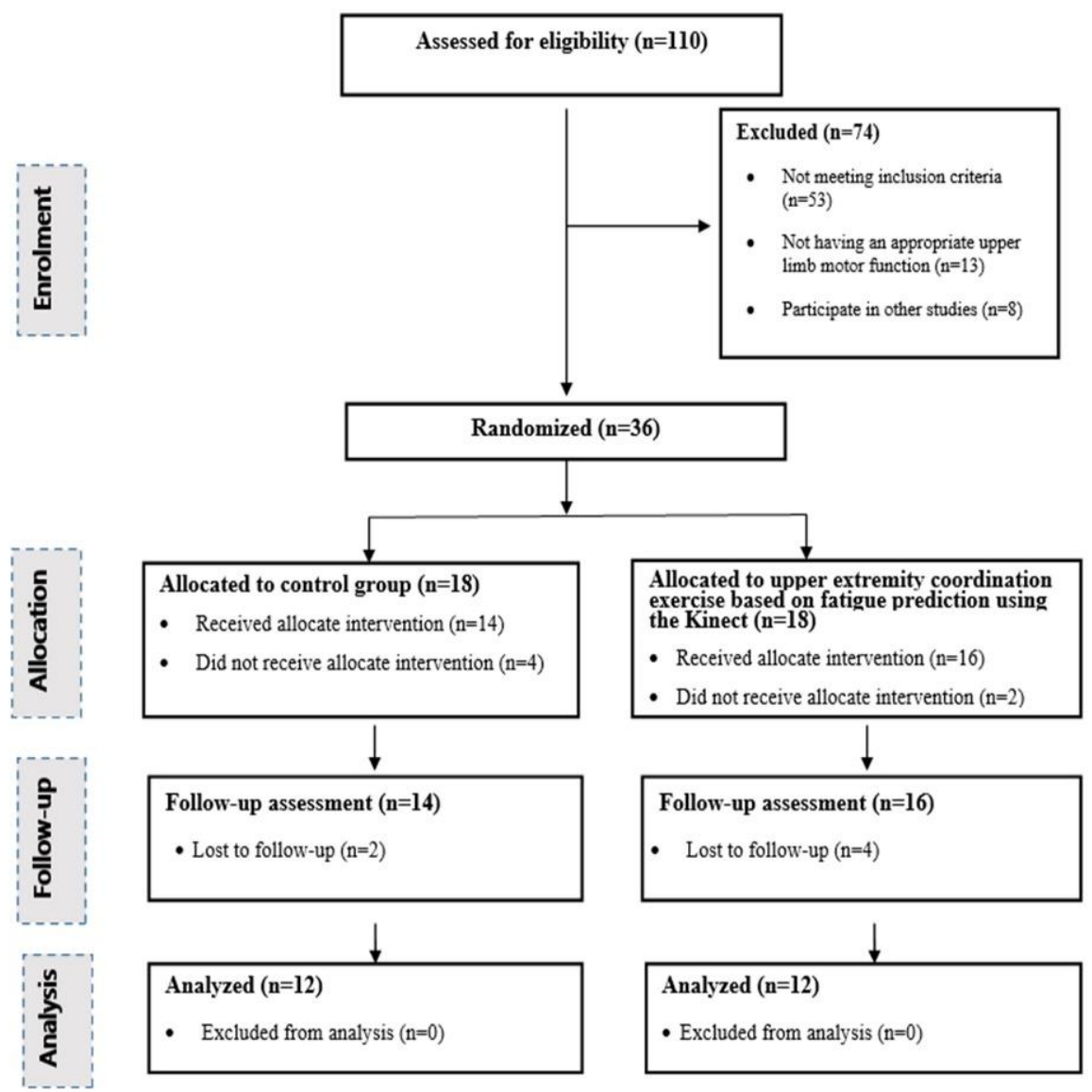

Figure 1. Participants' flow-diagram

Iranian Rehabilitation Journa

Also, shoulder proprioception evaluated by the SPST was significantly affected by the group $\times$ time interaction effect, but not the group or time main effect (Table 3). As depicted in Figure 4, a significant improvement in shoulder proprioception was found in both control and intervention groups at post-treatment, which was maintained at follow-up only in the intervention group.
The results indicated the significant main effect of time and the interaction effect of group $\times$ time on the fatigue severity $(\mathrm{P}<0.05)$, but the main effect of the group was not significant (Table 3 ). The results of multiple comparisons showed a significant reduction in fatigue severity in both control and intervention groups at post-treatment, which did not remain at follow-up (Figure 5).

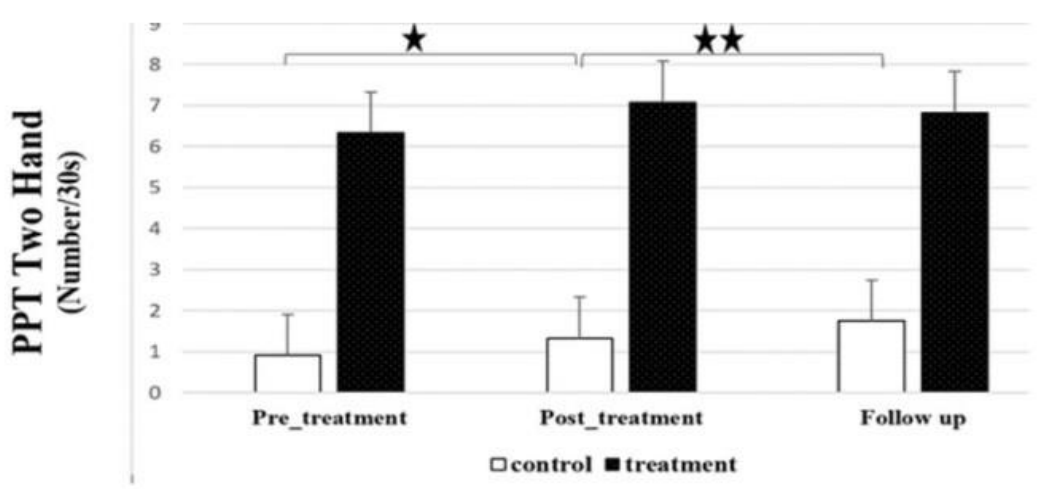

Iranian Rehabilitation \ourna

Figure 2. The plot of the group by time interaction effect for fine motor coordination of upper extremity assessed by bimanual subtest of Purdue Pegboard Test (PPT) for affected hand

${ }^{*} \mathrm{P} \leq 0.05 ; * * \mathrm{P} \leq 0.01$. 
Table 3. Comparison of functional outcomes measurement of pre-treatment, post-treatment and follow-up in chronic stroke survivors

\begin{tabular}{|c|c|c|c|c|c|c|c|c|c|c|}
\hline \multirow{3}{*}{$x^{2}+x^{2}$} & \multirow{3}{*}{ Variables } & \multicolumn{6}{|c|}{ Main Effect } & \multirow{2}{*}{\multicolumn{3}{|c|}{$\begin{array}{c}\text { Interaction Effect } \\
\text { GroupxTime }\end{array}$}} \\
\hline & & \multicolumn{3}{|c|}{ Group } & \multicolumn{3}{|c|}{ Time } & & & \\
\hline & & $\mathbf{F}$ & $\mathbf{P}$ & $\begin{array}{c}\text { Partial } \\
\eta^{2}\end{array}$ & $\mathbf{F}$ & $\mathbf{P}$ & $\begin{array}{c}\text { Partial } \\
\eta^{2}\end{array}$ & $\mathbf{F}$ & $\mathbf{P}$ & $\begin{array}{c}\text { Partial } \\
\eta^{2}\end{array}$ \\
\hline \multirow{4}{*}{$\begin{array}{l}\text { Motor Co- } \\
\text { ordination } \\
\quad \text { of UE }\end{array}$} & $\begin{array}{l}\text { Fine motor coordination of upper } \\
\text { extremity-Affected hand: PPT } \\
\text { (Number of pins per } 30 \text { seconds) }\end{array}$ & 0.83 & 0.37 & 0.03 & 2.5 & 0.09 & 0.1 & 0.14 & 0.86 & 0.007 \\
\hline & $\begin{array}{l}\text { Fine motor coordination of upper } \\
\text { extremity-Two hand: PPT } \\
\text { (Number of pins per } 30 \text { seconds) }\end{array}$ & 0.42 & 0.52 & 0.01 & 2.93 & 0.06 & 0.11 & 3.21 & 0.05 & 0.12 \\
\hline & $\begin{array}{l}\text { Fine motor coordination of upper } \\
\text { extremity-montage: PPT } \\
\text { (Number of pins per } 30 \text { seconds) }\end{array}$ & 0.001 & 0.98 & 0.000 & 3.04 & 0.05 & 0.12 & 0.007 & 0.99 & 0.00 \\
\hline & $\begin{array}{l}\text { Gross motor coordination of up- } \\
\text { per extremity-Affected hand: BBT } \\
\text { (Number of blocks per } 60 \text { sec- } \\
\text { onds) }\end{array}$ & 0.13 & 0.71 & 0.006 & 9.52 & 0.001 & 0.30 & 0.38 & 0.64 & 0.017 \\
\hline \multirow{4}{*}{$\begin{array}{l}\text { Motor } \\
\text { Function } \\
\text { of UE }\end{array}$} & $\begin{array}{l}\text { MAM-16 } \\
(0-64)\end{array}$ & 0.16 & 0.69 & 0.007 & 10.12 & 0.001 & 0.31 & 0.25 & 0.29 & 0.05 \\
\hline & $\begin{array}{l}\text { WMFT: Functional Ability } \\
(0-75)\end{array}$ & 0.025 & 0.87 & 0.001 & 19.84 & $<0.0001$ & 0.90 & 0.036 & 0.85 & 0.002 \\
\hline & $\begin{array}{l}\text { WMFT-Time } \\
\text { (seconds) }\end{array}$ & 0.1 & 0.74 & 0.005 & 20.34 & $<0.0001$ & 0.48 & 0.71 & 0.49 & 0.031 \\
\hline & $\begin{array}{l}\text { ARAT } \\
(0-57)\end{array}$ & 0.27 & 0.60 & 0.01 & 7.29 & 0.008 & 0.24 & 0.46 & 0.53 & 0.02 \\
\hline $\begin{array}{l}\text { Power } \\
\text { Grasp of } \\
\text { UE }\end{array}$ & $\begin{array}{l}\text { Dynamometer } \\
\qquad(\mathrm{Kg})\end{array}$ & 0.001 & 0.97 & 0.000 & 8.94 & 0.001 & 0.28 & 0.37 & 0.68 & 0.01 \\
\hline $\begin{array}{l}\text { Function of } \\
\text { Shoulder } \\
\text { Propriocep- } \\
\text { tion Sens } \\
\text { on the } \\
\text { Affected } \\
\text { Side }\end{array}$ & $\begin{array}{l}\text { Average error recognition of } \\
\text { angle on the shoulder: SPST } \\
\text { (degree) }\end{array}$ & 0.25 & 0.061 & 0.01 & 2.15 & 0.14 & 0.08 & 0.069 & 0.046 & 0.031 \\
\hline $\begin{array}{l}\text { Function of } \\
\text { Elbow Pro- } \\
\text { prioception } \\
\text { Sens on the } \\
\text { Affected } \\
\text { Side }\end{array}$ & $\begin{array}{l}\text { Average error recognition of } \\
\text { angle on the elbow: EPST } \\
\text { (degree) }\end{array}$ & 1.16 & 0.029 & 0.053 & 6.78 & 0.003 & 0.024 & 0.059 & 0.055 & 0.027 \\
\hline \multirow{2}{*}{$\begin{array}{l}\text { Participa- } \\
\text { tion }\end{array}$} & $\begin{array}{l}\text { COPM-Performance } \\
(0-10)\end{array}$ & 0.85 & 0.36 & 0.03 & 11.33 & 0.002 & 0.34 & 0.26 & 0.65 & 0.012 \\
\hline & $\begin{array}{c}\text { COPM-Satisfaction } \\
(0-10)\end{array}$ & 1.04 & 0.31 & 0.04 & 11.26 & $<0.0001$ & 0.33 & 0.49 & 0.61 & 0.02 \\
\hline $\begin{array}{l}\text { Activity of } \\
\text { Daily Living }\end{array}$ & $\begin{array}{l}\text { SH-BI } \\
(0-100)\end{array}$ & 0.38 & 0.54 & 0.01 & 2.78 & 0.10 & 0.11 & 0.12 & 0.74 & 0.005 \\
\hline Fatigue & $\begin{array}{c}\text { MFI } \\
(1-100)\end{array}$ & 0.61 & 0.26 & 0.01 & 16.70 & $<0.0001$ & 0.43 & 3.98 & 0.03 & 0.15 \\
\hline
\end{tabular}

Bold: P $\leq 0.05$; PPT: Purdue and Pegboard Test; BBT: Box and Block Test; MAM-16: Manual Ability Measure-16; WMFT: Wolf Motor Function Test; ARAT: Action Research Arm Test; SPST: Shoulder Position Sense Test; EPST: Elbow Position Sense Test, COPMPerformance: Canadian Occupational Performance Measure-Performance; COPM-Satisfaction: Canadian Occupational Performance Measure-Satisfaction; SH-BI: Shah-Barthel Index, MFI: Multi-dimensional Fatigue Inventory, UE: Upper Extremity 


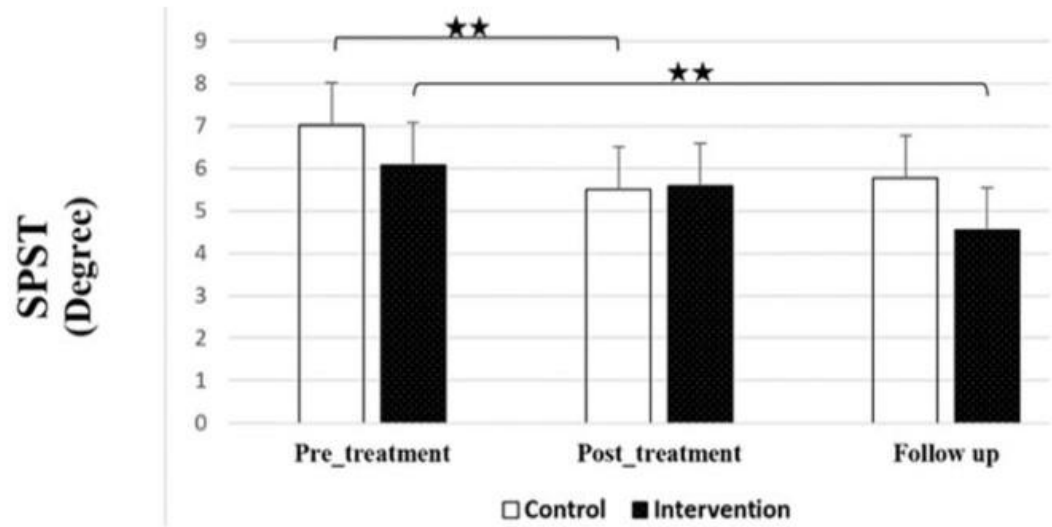

Iranian Rehabilitation Journal

Figure 3. The plot of the group by time interaction effect for shoulder proprioception evaluated by Sense Test (SPST)

** $\mathrm{P} \leq 0.01$.

Moreover, independence in ADLs assessed by SH-BI was not affected by the main effect of time and group or their interaction effect (Table 3).

\section{Discussion}

The current study was conducted to investigate the effects of UE coordination exercises based on fatigue prediction on the UE sensory-motor functions in chronic stroke survivors. The results of this study showed significant improvement of UE motor functions (i.e. fine manual dexterity assessed by BBT and PPT, respectively, WMFT-Functional ability and WMFT-time, ARAT, and MAM-16 score), shoulder and elbow proprioception, grip strength, and occupational performance and satisfaction of occupational performance (measured by COMP), as well as a significant reduction in fatigue severity in both the control and intervention groups. Significant improvement in BBT score $[6,24]$, WMFT-
Functional ability and WMFT-time [25-27], and ARAT score $[23,28]$, grip strength $[6,24]$, and shoulder proprioception [29] has also been reported previously in chronic stroke survivors following bimanual UE exercises. However, following receiving the assigned exercises, no significant difference was found between the control and intervention groups regarding these outcome measures, which may be explained by the small sample size. Thus, future studies are suggested to be done on the effects of UE coordination exercises on UE sensorymotor functions using a larger sample size.

Symmetrical bilateral exercises employ many forms of bilateral neural coupling mechanisms to enhance the plasticity of the central nervous system that activates the same neural networks in both brain hemispheres and reduces interhemispheric inhibition [7]. Besides, more corticospinal pathways are recruited in bilateral arm exercises because the unaffected UE is involved in these

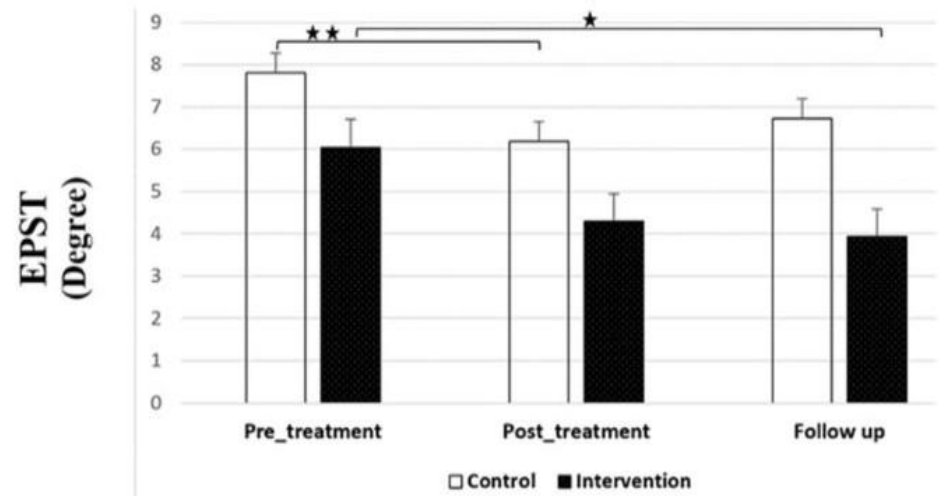

Iranian Rehabilitation Journa

Figure 4. The plot of the group by time interaction effect for elbow proprioception evaluated by Elbow Position Sense Test (EPST)

${ }^{*} \mathrm{P} \leq 0.05 ;{ }^{* *} \mathrm{P} \leq 0.01$. 


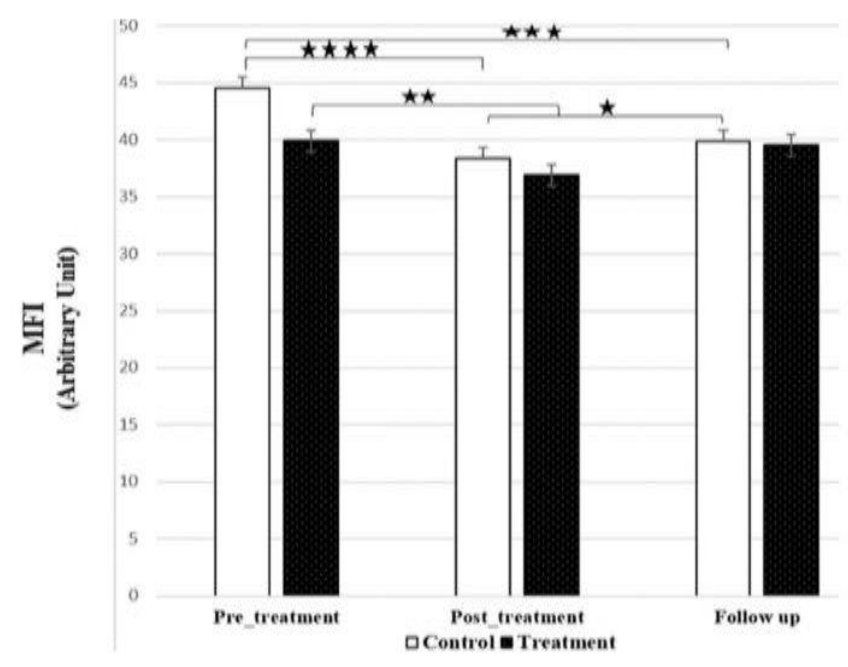

Iranian Rehabilitation Dournal

Figure 5. The plot of the group by time interaction effect for the severity of fatigue measured by Multi-dimensional Fatigue Inventor elbow proprioception evaluated Elbow Position Sense Test (EPST)

${ }^{*} \mathrm{P} \leq 0.05$; ** $\mathrm{P} \leq 0.01 ;$ *** $\mathrm{P} \leq 0.001$; *** $\mathrm{P} \leq 0.0001$.

exercises in addition to the affected UE [27]. This leads to less energy consumption for exercises, which in turn results in performing exercises over a shorter time [7]. In patients with chronic motor impairments after stroke, specific bilateral repetitive upper extremity rehabilitation therapy appears to induce reorganization in bilateral, but mainly in contralesional, hemisphere networks and in the cerebellum, and may operate by recruiting these brain areas to provide functional benefits, such as improvement of motor function [27]. Since finger movement exercises were performed in the form of gross and fine grips in both control and intervention groups of the present study, this group was also expected to show significant improvement of UE motor functions at post-treatment in comparison with pre-treatment evaluation. In line with previous studies [30], the significant improvement observed in the UE motor function in the current study may result in a significant enhancement of the occupational performance and satisfaction of occupational performance in both control and intervention groups.

In the current study, bilateral UE exercises based on fatigue prediction were provided in the intervention group. Predicting fatigue made it possible to increase the duration of exercises and the number of exercises performed in each session. Based on motor learning principles, increasing the number of exercises plays an important role in motor learning and consolidation. Thus, it is possible that predicting early fatigue during exercises and changing the type of exercises to increase rehabilitation efficiency in the intervention group led to a significant improve- ment in the motor function of this group after receiving the exercises. Moreover, a significant reduction in fatigue severity observed in both control and intervention groups in the present study may also be involved in the improvement in UE motor function of both groups. Fatigue may induce a reduction in the activation level of UE muscles, which could decrease function. In addition to the UE motor functions, fatigue may negatively affect joint proprioception through deficiencies in muscle mechanoreceptors activation or a decrease in muscle function.

The proprioceptive impairment due to muscle fatigue could be caused by changes in the discharge patterns of muscle afferents due to metabolites build-up, leading to potential altered muscle spindles information [31-33]. Further, in a recent systematic review, it has been suggested that rehabilitation interventions, including repetitive exercises, lead to improved strength in stroke survivors [34], as evidenced by increased grip strength in the present study. Moreover, the negative effects of fatigue on occupational performance and roles, such as social participation, return to work, driving, etc. have been reported previously [35]. Since in this study the fatigue severity was reduced in both control and intervention groups, it can be assumed that the reduction in fatigue severity led to improved occupational performance.

However, the findings of this study showed that independence in ADLs evaluated by SH-BI did not change significantly following receiving exercises in the control or intervention groups. This finding may be explained by the fact that the participants in the current study were 
in the Brunnstrom recovery stage 4, 5, or 6 and most of them (11 participants in each group) had no dependence or minimum dependence in ADLs according to the SHBI score. Rodgers et al. and Duncan et al. also found a significant improvement in the UE function of stroke survivors without any change in their independence in ADLs following rehabilitation interventions [36, 37].

\section{Conclusion}

The results of this study showed a significant improvement in UE motor functions, shoulder and elbow proprioception, grip strength, and occupational performance and satisfaction of occupational performance, as well as a significant reduction in fatigue severity in chronic stroke survivors in both control and intervention groups. In this study, sensory-motor functions were assessed by behavioral tests. However, assessments of UE functions using motion analysis and magnetic resonance imaging may provide further information regarding the effects of UE coordination exercises based on fatigue prediction.

\section{Ethical Considerations}

\section{Compliance with ethical guidelines}

The ethical approval was obtained from the Ethics Committee of Iran University of Medical Sciences (IR.IUMS.REC.1397.582) and the study protocol was registered at Iranian Registry of Clinical Trials (IRCT20140416017301N6).

\section{Funding}

The paper was extracted from the MSc. thesis of the first author's at the Department of Occupational Therapy in Iran University of Medical Sciences.

\section{Authors' contributions}

All authors equally contributed in preparing this article.

\section{Conflict of interest}

The authors declared no conflict of interest.

\section{Acknowledgments}

The authors would like to greatly thank the director of the Dr. Javad Mowafaghian Research Center of Intelligent Neuro-Rehabilitation Technologies and the director of the rehabilitation department, Shafa-Yahyaeian Hospital, and all those who participated in the implementation of this research.

\section{References}

[1] Hoang CL, Salle JY, Mandigout S, Hamonet J, Macian-Montoro F, Daviet JC. Physical factors associated with fatigue after stroke: An exploratory study. Topics in Stroke Rehabilitation. 2012; 19(5):369-76. [PMID]

[2] Rashedi E, Nussbaum MA. A review of occupationally-relevant models of localized muscle fatigue. International Journal of Human Factors Modelling and Simulation. 2015; 5(1):61-80. [DOI:10.1504/IJHFMS.2015.068119]

[3] Mead G, Bernhardt J, Kwakkel G. Stroke: Physical fitness, exercise, and fatigue. Stroke Research and Treatment. 2012; 2012:632531. [DOI:10.1155/2012/632531] [PMID] [PMCID]

[4] Knorr S, Rice CL, Garland SJ. Perspective on neuromuscular factors in poststroke fatigue. Disability \& Rehabilitation. 2012 34(26):2291-9. [PMID]

[5] Lai CH, Sung WH, Chiang SL, Lu LH, Lin CH, Tung YC, et al. Bimanual coordination deficits in hands following stroke and their relationship with motor and functional performance. Journal of Neuroengineering and Rehabilitation. 2019 16(1):101. [DOI:10.1186/s12984-019-0570-4] [PMID] [PMCID]

[6] Han KJ, Kim JY. The effects of bilateral movement training on upper limb function in chronic stroke patients. Journal Physical Therapy Science. 2016; 28(8):2299-302. [DOI:10.1589/ jpts.28.2299] [PMID] [PMCID]

[7] Hassanpour M, Hoseini SA, Aboutalebi S, Rahgozar M Sarafraz Z. [The effect of bilateral activities on the improvement of upper limb function in CVA patients (Persian)]. Kermanshah University of Medical Sciences. 2011; 15(1): e69717. https://brief.land/jkums/articles/69717.html

[8] Baird JF, Gaughan ME, Saffer HM, Sarzynski MA, Herter TM, Fritz SL, et al. The effect of energy-matched exercise intensity on brain-derived neurotrophic factor and motor learning. Neurobiology of Learning and Memory. 2018; 156:33-44. [DOI:10.1016/j.nlm.2018.10.008] [PMID] [PMCID]

[9] Zhou H, Hu H. Human motion tracking for rehabilitationA survey. Biomedical Signal Processing and Control. 2008, 3(1):1-18. [DOI:10.1016/j.bspc.2007.09.001]

[10] Amrani MZEA, Achour N. Serious game based on skeleton shape matching for functional rehabilitation exercises. Paper presented at: Proceedings of the 2019 3rd International Conference on Automation, Control and Robots. 2019. 11-13 October 2019; Prague, Czech Republic. [DOI:10.1145/3365265.3365279]

[11] Yancosek KE, Howell D. A narrative review of dexterity assessments. Journal of Hand Therapy. 2009; 22(3):258-70. [DOI:10.1016/j.jht.2008.11.004] [PMID]

[12] Hsieh CL, Hsueh IP, Chiang FM, Lin PH. Inter-rater reliability and validity of the action research arm test in stroke patients. Age and Ageing. 1998; 27(2):107-13. [DOI:10.1093/ ageing/27.2.107] [PMID]

[13] Chen C, Granger C, Peimer C, Moy O, Wald S. Manual Ability Measure (MAM-16): A preliminary report on a new patient-centered and task-oriented outcome measure of hand function. Journal of Hand Surgery. 2005; 30(2):207-16. [DOI:10.1016/J.JHSB.2004.12.005] [PMID] 
[14] Iwamoto K, Yoshio M, Takata Y, Kozuka N. Reliability and validity of standing balance assessment index using a hand-held dynamometer in stroke patients. Journal of Physical Therapy Science. 2016; 28(11):3158-61. [DOI:10.1589/ jpts.28.3158] [PMID] [PMCID]

[15] Colham F, Lewis J, Lee H. The reliability of one vs. Three grip trials in symptomatic and asymptomatic subjects. Jour nal of Hand Therapy. 2006; 19(3):318-26. [DOI:10.1197/j. jht.2006.04.002] [PMID]

[16] Glendon K, Hood V. Upper limb joint position sense during shoulder flexion in healthy individuals: A pilot study to develop a new assessment method. Shoulder \& Elbow. 2016; 8(1):54-60. [DOI:10.1177/1758573215603916] [PMID] [PMCID]

[17] Dover G, Powers ME. Reliability of joint position sense and force-reproduction measures during internal and external rotation of the shoulder. Journal of Athletic Training. 2003; 38(4):304-10. [PMID]

[18] Juul-Kristensen B, Lund H, Hansen K, Christensen H, Danneskiold-Samsøe B, Bliddal $\mathrm{H}$. Test-retest reliability of joint position and kinesthetic sense in the elbow of healthy subjects. Physiothery Theory and Practice. 2008; 24(1):65-72. [PMID]

[19] Tagharrobi Z, Sharifi K, Sooky Z. [Psychometric evaluation of Shah version of modified Barthel index in elderly people residing in Kashan Golabchi nursing home (Persian)]. Feyz. 2011; 15(3):213-24. http:/ / feyz.kaums.ac.ir/article-1-1241-en.html

[20] Dehghan L, Dalvand H, Pourshahbaz A. [Translation of Canadian occupational performance measure and testing Persian version validity and reliability among Iranian mothers of children with cerebral palsy (Persian)]. Journal Modern Rehabilition. 2015; 9(4):25-31. http://mrj.tums.ac.ir/article1-5349-en.html

[21] Cup EH, Scholte op Reimer WJ, Thijssen MC, van Kuyk-Minis MA. Reliability and validity of the Canadian Occupational Performance Measure in stroke patients. Cinial Rehabilitation. 2003; 17(4):402-9. [DOI:10.1191/0269215503cr635oa] [PMID]

[22] Saffari M, Naderi MK, Piper CN, Koenig HG. Multidimensional fatigue inventory in people with hepatitis B infection: Cross-cultural adaptation and psychometric evaluation of the Persian Version. Gastroenterology Nursing. 2017; 40(5):380-92. [DOI:10.1097/SGA.0000000000000250] [PMID]

[23] Meng G, Meng X, Tan Y, Yu J, Jin A, Zhao Y, et al. Shortterm efficacy of hand-arm bimanual intensive training on upper arm function in acute stroke patients: A randomized controlled trial. Frontiers in Neurology. 2018; 8:726. [DOI:10.3389/fneur.2017.00726] [PMID] [PMCID]

[24] Lee S, Kim Y, Lee BH. Effect of virtual reality-based bilateral upper extremity training on upper extremity function after stroke: A randomized controlled clinical trial. Occupational Therapy International. 2016; 23(4):357-68. [DOI:10.1002/ oti.1437] [PMID]

[25] Hijmans JM, Hale LA, Satherley JA, McMillan NJ, King MJ. Bilateral upper-limb rehabilitation after stroke using a movement-based game controller. Journal of Rehabilitation Research and Development . 2011; 48(8):1005-13. [PMID]

[26] Wu CY, Chuang LL, Lin KC, Chen HC, Tsay PK. Randomized trial of distributed constraint-induced therapy versus bilateral arm training for the rehabilitation of upper-limb motor control and function after stroke. Neu- rorehabilitation and Neural Repair. 2011; 25(2):130-9. [DOI:10.1177/1545968310380686] [PMID]

[27] Luft AR, McCombe-Waller S, Whitall J, Forrester LW, Macko R, Sorkin JD, et al. Repetitive bilateral arm training and motor cortex activation in chronic stroke: A randomized controlled trial. JAMA. 2004; 292(15):1853-61. [DOI:10.1001/ jama.292.15.1853] [PMID] [PMCID]

[28] Sethy D, Sahoo S, Kujur ES, Bajpai P. Stroke upper extremity rehabilitation: Effect of bilateral arm training. International Journal of Health \& Allied Sciences. 2018; 7(4):217. https:// www.ijhas.in $/$ article.asp?issn=2278-344X; year=2018; =Sethy

[29] Jung KM, Choi JD. The effects of active shoulder exercise with a sling suspension system on shoulder subluxation proprioception, and upper extremity function in patients with acute stroke. Medical Science Monitor. 2019; 25:4849-55. [DOI:10.12659/MSM.915277] [PMID] [PMCID]

[30] Almhdawi KA, Mathiowetz VG, White M, delMas RC. Efficacy of occupational therapy task-oriented approach in upper extremity post-stroke rehabilitation. Occupational Therapy International. 2016; 23(4):444-56. [DOI:10.1002/oti.1447] [PMID]

[31] Proske U. Exercise, fatigue and proprioception: A retrospective. Experimental Brain Research. 2019; 237(10):2447-59. [DOI:10.1007/s00221-019-05634-8] [PMID]

[32] Zabihhosseinian M, Holmes MW, Murphy B. Neck muscle fatigue alters upper limb proprioception. Experimental Brain Research. 2015; 233(5):1663-75. [DOI:10.1007/s00221-0154240-x] [PMID]

[33] Abd-Elfattah HM, Abdelazeim FH, Elshennawy S. Physical and cognitive consequences of fatigue: A review. Journal of Advanced Reaserch. 2015; 6(3):351-8. [DOI:10.1016/j. jare.2015.01.011] [PMID] [PMCID]

[34] de Sousa DG, Harvey LA, Dorsch S, Glinsky JV. Interventions involving repetitive practice improve strength after stroke: A systematic review. Journal of Physiotherapy. 2018; 64(4):210-21. [DOI:10.1016/j.jphys.2018.08.004] [PMID]

[35] Flinn NA, Stube JE. Post-stroke fatigue: Qualitative study of three focus groups. Occupational Therapy International. 2010; 17(2):81-91. [DOI:10.1002/oti.286] [PMID]

[36] Rodgers H, Mackintosh J, Price C, Wood R, McNamee P, Fearon $T$, et al. Does an early increased-intensity interdisciplinary upper limb therapy programme following acute stroke improve outcome? Clinical Rehabilitation.2003; 17(6):579-89. [DOI: 10.1191/0269215503cr652oa] [PMID]

[37] Duncan P, Richards L, Wallace D, Stoker-Yates J, Pohl P, Luchies $\mathrm{C}$, et al. A randomized, controlled pilot study of a home-based. Exercise program for individuals with mild and moderate stroke. Stroke 1998; 29(10):2055-60. [DOI 10.1161/01.str.29.10.2055] [PMID] 